\title{
EDUCATION AND THE ADEQUACY OF OPTIONS AN INTERVIEW WITH JOHN WHITE
}

Mitja Sardoč and John White

\begin{abstract}
Mitja Sardoč's interview with John White discusses a neglected aspect of the educational goal of equipping learners to lead a life of autonomous well-being - trying to ensure that they have adequate options from which to choose worthwhile activities and relationships. Following a brief account of the nature of autonomous well-being, White outlines and critiques Joseph Raz's views on the adequacy of options in general as well as an earlier inadequate approach of his own to this topic in relation to the school curriculum. He then picks up and critically discusses Eamonn Callan's curricular suggestions about how to open up a range of options. Drawing on both these discussions, the interview then leads to a threefold proposal about how schools and other agencies could go about providing the adequate range required. The last two short sections underline the wider changes needed in society if the work of these educational institutions is to bear fruit.
\end{abstract}

Mitja Sardoč: You have often written about personal well-being in the context of educational aims. I know you have sometimes changed your mind on what this concept involves. Where do you stand on this topic today?

You are right. For over forty years I've held that a good education has much, but not everything, to do with equipping people to lead flourishing lives - lives of personal wellbeing. And it's also true that my understanding of this concept has changed over the years. I have recently been exploring an aspect of the concept which in the past I have sometimes mishandled, sometimes overlooked. Perhaps I could come on to that in a minute.

First, though, I must answer your question about where I stand on the topic of well-being today. Influenced by Joseph Raz's writings among others, I have held for some time that personal well-being has two aspects. It requires the satisfaction of a range of necessary conditions such as the meeting of biological needs for food, shelter etc as well as such things as self-respect and a degree of social recognition. The second aspect is about the goals one pursues given that these necessary conditions are met. A life of well-being is one in which the agent is wholeheartedly and successfully engaged for much of it in intrinsically worthwhile activities and relationships (Raz 1994: 3). Whether these activities and relationships can be stated, as some philosophers have attempted to state them, in an 'objective list' is moot. I have been convinced over the years that a view like the one I held in the 1970s and the 1980s (eg in White 1973, 1982), that one's well-being consists in the successful pursuit of goals that one has chosen on reflection to pursue, is inadequate. This would make personal well-being too subjective a matter, dependent on an individual's preferences. It would allow in ways of life I now would reject as flourishing ones, such as Rawls' celebrated imaginary example of the man who more than anything else in his life wants to spend his time counting the blades of grass in a city park and succeeds in doing so (Rawls 1972: 432). But if pursuits like these are to be dismissed as not intrinsically worthwhile, what pursuits - activities and relationships - are to be included? 
Does this point to some kind of objective criteria for what counts as intrinsically worthwhile pursuits? Is there what some writers have called 'an objective list' of these?

My short answer is 'No'. But I need to give this some background. I have been influenced by Raz (2003: 36 and passim) in thinking that what he calls the 'life-building values', those that 'can give a meaning and a purpose to life' depend on the existence of social forms. He sees these as developing over time as new forms and genres of art, for example, or medical practice, or new kinds of close relationship - based for example on equality of status between marital partners - have appeared on the scene. What makes these values not relative to the culture in which they first appeared is that they continue to exist even when these original circumstances are no more: music lovers still value Mozart's music highly even though the age of princes and their courts is in the past.

There are other values than the 'life-building ones' (ibid.). These include sensual and perceptual pleasures of a momentary sort - ie when not integrated into larger patterns of activity - like eating an ice cream or feeling the sun's warmth on one's face. Since what I want to talk about is the nature of education, a life-building enterprise par excellence, these can reasonably be ignored.

I think Raz's perspective helps us to see why Rawls's grass counter is not engaging in something intrinsically valuable. He is not enjoying isolated momentary pleasures. He may well enjoy the smell and sight of the grass he is counting, but this is integrated into his mathematical activity. Aspects of what he is doing are certainly socially dependent: there are all sorts of such activities from astronomy to psephology that involve the social practice of counting. The problem is that the particular kind of counting we have in Rawls - of blades of grass in a park - is not anchored in a recognisable social form. If it is a genre of counting, it is not a genre that has developed historically within a larger cultural pursuit - as detective or romantic fiction have developed, for instance, as sub-forms of the novel. It cannot, despite the artificially constructed nature of the example, genuinely give meaning or purpose to a person's life.

So much for the background to my answer to your question. The Razian approach does not lead, as in some other writers, to the formulation of an 'objective list' of intrinsic (lifebuilding) values. What we have instead is a certain measure of agreement among those familiar with a genre that, owing to the particular combination of values embodied in it, such and such an activity has more to it from a life-enhancing point of view than other examples of the genre. Examples might be reading Pushkin's Eugene Onegin rather than a mediocre long poem; working as a gifted primary teacher in an outstanding school rather than as a Thomas Gradgrind; watching Fawlty Towers rather than a run-of-the-mill TV comedy; enjoying a long lasting relationship based on mutual respect and shared interests rather than a series of one night stands. This certain measure of agreement leaves plenty of room for differences of weighting - not surprising given the mixture of values that is found in examples like these. If one wishes to speak of a residual 'subjectivity' in this connection, it is far from that where this term is used to label purely individual preferences, including, as in my own earlier thinking (eg White 1973), a person's 'post-reflective' preferences. Any divergence of values occurs against the background of a broad agreement with a culture about what is valuable within an area or genre. 
You haven't mentioned autonomy in your account of well-being, even though It has always played a role in your thinking, hasn't it, not least in your views on educational aims?

That's right. I have always thought that a life of well-being requires autonomy on the part of the agent enabling them to make their own independent choices of pursuits to follow from an array of options; although before I read Raz in the 1980s, I took it that this was a conceptual matter. I now think otherwise. In other words, well-being does not necessarily involve autonomy. One rightly talks about lives of greater or lesser well-being in traditionbound societies where autonomous choice of options is rare or non-existent. But it is broadly true for nearly everyone in a complex industrial society like our own that a life of well-being is an autonomous one. It is dependent on people making their own choices about partners, type of work, where they live, free time pursuits and so on (Raz 1986: 369-70).

A life of autonomous well-being requires one not only to make choices among worthwhile activities and relationships, but also gradually to establish priorities among one's preferences as one constructs complex, interrelated hierarchies of goals and sub-goals culminating in those more pervasive in one's life.

\section{Are there other ways in which your views on autonomy have changed?}

Yes - with regard to the claim that autonomy requires choice among worthwhile options. This is an especially important topic for educators since it bears closely on the shape of the curriculum (using this term broadly to cover the content of education of all sorts, not only in schools). When I first wrote on this topic in the 1970s in connection with the school curriculum, my view was that as part of a pupil's education for autonomy, we must ensure 'that he (sic) knows about as many activities and ways of life as possible' -or, in another formulation, 'about the whole range of things' (White 1973: 25) - which he may want to choose for their own sake' (p.22)

Why did I say 'as many activities and ways of life as possible'/'the whole range of things'? Does a life of autonomous well-being really demand such a comprehensive knowledge of possibilities? This seems to me now an impossibly ambitious and unnecessary aim, as Keith Thompson was one of the first to point out in 1975 (Thompson and White 1975: Section 2), followed by Eamonn Callan (1988). I will say more about why my views have changed in a moment. I think now that I was led in this maximising direction in the 1970 s by the excessively subjective account of personal well-being which I then held and to which I have referred above. When delineating the nature of personal well-being, I could not see any good reasons for limiting the range of intrinsically worthwhile activities from which autonomous persons could choose - for instance, to those concerned with the pursuit of truth highlighted by Richard Peters in Ethics and Education (Peters 1966 ch.5). Any proposed list of such items - intellectual, artistic, practical etc. or some combination of these - could present a potential threat to an autonomous life. This, I thought, was because any such list was bound to reflect the subjective views of its compiler. In a school context, this would mean imposing arbitrary preferences on students. It could be a subtle form of system-based indoctrination to lead them to feel that they must come to love disciplined intellectual enquiry for its own sake when there were no good reasons for this. It seemed the only 
acceptable alternative would be to open the range of their possible options as far as possible.

\section{But you no longer think so?}

No. Joseph Raz and Eamonn Callan have helped me here. In The Morality of Freedom Raz says that for a person to enjoy an autonomous life there must, among other things, 'be adequate options available for him to choose from' (Raz 1986: 373). 'Adequate options' is much less demanding a requirement than 'all possible options'. What counts as 'adequate'? Raz gives examples of people who either have no non-trivial options to choose from or whose only option is to do something to keep out of the clutches of a fierce carnivorous animal (p.373-4). These are clearly cases where the range of options is inadequate. As for a positive account of what range of options is adequate, Raz states that for his present purposes in the book 'we do not require a general doctrine of the adequacy of options' (p.373). How much control is required for an autonomous life is, he says, 'an enormously difficult problem' (ibid.). All he thinks he can say generally about the adequacy of options is that

To be autonomous and to have an autonomous life, a person must have options which enable him to sustain throughout his life activities which, taken together, exercise all the capacities human beings have an innate drive to exercise, as well as to decline to develop any of them. (p. 375).

He says further that

This formulation, far too abstract to serve as a direct guide to social policy, needs further elaboration. It needs, for example, to be cashed in terms of the options available in a particular society. It is however a virtue of the formulated test that it is not culture-bound. It points to the way in which the options available to different cultures can be evaluated and compared.

For Raz, then, adequacy is to be understood in terms of 'all the capacities human beings have an innate drive to exercise'. He says of these that 'we have innate drives to move around, to exercise our bodies, to stimulate our senses, to engage our imagination and our affection, to occupy our mind. To a considerable degree culture and civilisation consist in training and channelling these innate drives'.

It is noteworthy that the innate drives mentioned all seem as it were tailor-made for being the basis of what are often seen as worthwhile options - like (respectively) visits to interesting places, sport, the visual and musical arts, literature, personal love, intellectual pursuits. Innate drives to be aggressive or to dominate over others, which are not so tailormade, are not included in the list. This may suggest that what lies behind Raz's claim is an idea of worthwhileness that comes from some other source than our innate drives. As it stands, his argument looks open to the common objection made against naturalistic accounts of values that they do not explain how one can get from statements of what empirically is the case (we have such and such innate drives) to an evaluative conclusion (capacities based on these drives are worthwhile options for the autonomous person). 


\section{Could you develop this a bit further?}

The objection based on aggressiveness and domination may be defused by pointing to ethically defensible pursuits such as boxing or benign leadership of institutions within a democratic society, where these innate drives have been trained and channelled by culture and civilisation. But this suggests a different sort of problem for Raz's account: not its naturalism but its emptiness. Whatever capacities are exercised or not according to the autonomous person's choice, any and all of them have to depend ultimately on innate human drives. Pointing to an innate basis does not take us very far at all in determining what would be included in an adequate range of options. ${ }^{1}$

But I do not want to lose sight of the value of Raz's 'adequate options' approach as an alternative to the 'all possible options' view. The latter is simply unrealistic. Having a limited number of options but enough for a life of autonomous well-being makes more sense, even though we have as yet not got much further in cashing out this 'enough'. As Raz says, this constitutes an 'enormously difficult problem'. We will see later how far we can get with it.

A related way in which Raz's 'adequate options' is preferable to 'all possible options' is this. Raz makes it clear that he is talking about the options available to people in the circumstances in which they find themselves. The 'Hounded Woman' of his example, who is pursued by a fierce carnivorous beast, has just the one option of trying to keep out of its way. Embroidering Raz, perhaps there is something special about this woman which makes her a target, while other people living on her island are not in danger like her. Within the island community as a whole there are, we can suppose, hundreds of possible worthwhile options, from sailing to studying astronomy to pursuing a love life. But these are not options for the Hounded Woman: she has only one - survival.

This is important to bear in mind when looking at autonomous well-being and educating people for it. The options that come into this are options that are available to people, in that they are in a position to choose them if they wish. A slave in America's deep south could not choose to become a lawyer or a teacher even though these options existed in the USA of that time. Forty years ago in the UK people could not choose on-line publishing as a career, since the option was then unavailable. When I wrote in the 1970s of introducing all learners to all possible options, it was not clear what constraints if any I saw on this. I said nothing about being in a position to choose or reject something. Would 'all possible options' for a congenitally blind child have included looking at works of art?

\section{You mentioned Eamonn Callan as another person who has led you to change your views on the range of options necessary for autonomy. Could you say more about this?}

Eamonn Callan touches on the 'adequate options' issue, if not by name, in his Autonomy and Schooling (1988). He describes the hypothetical case of a child whose education is built around her artistic inclinations. She 'might end up with little understanding of mathematics and the sciences. Her choice of a life that revolves around the arts may have been a highly autonomous one' (p.76). He goes on to say that if so, 'then her curriculum would indeed be immensely liberating. It would secure for her a range of options pertaining to things she is deeply interested in doing' (p.77). 
We can round out Callan's account by supposing that this person goes on to live a fulfilling life as a book illustrator, a mother of two children with a number of close friends, and interests in hill walking, modern art, the opera, local politics. On anyone's reckoning, this would count as a life replete in well-being. What it shows is that to achieve this one's education does not have to have opened up for one a vast range of options, let alone 'all possible' ones. And it would surely be odd to claim that the person in question has not been autonomous in her choice of options, assuming that she has made these choices independently, without coercion by others.

Is this example useful in helping us to determine what an adequate range of options should be in general and in education? Callan uses it to support his case that the school curriculum should revolve around and develop children's interests, not, for example, disciplines of knowledge imposed on them by their school or national community the study of which they may find dull or boring. In one way Callan's approach is reminiscent of Raz's. Both of them look to psychological facts about us as a guide to adequacy of options. Raz focuses on our shared innate drives as shaped by culture, while Callan is more attentive to individual differences and highlights the inclinations that children show early on towards this area of interest rather than that.

If we take Callan's example as I have elaborated it, one thing we might say about it is that the woman who went on to be a book illustrator and lead a full life may have been very lucky. In other circumstances she may not have been able to make a career in the area she loved but had to make do with a poorly-paying job which limited her ability to pursue her interests. If she had had mathematics and science as strings to her bow as well as the arts, she might have been more successful in achieving a fulfilling life. These would have opened up a wider set of options, including vocational ones, thus giving her greater insurance against misfortune. They might among other things proved interesting in themselves as well as gateways to other things. In his book Callan seems to assume too readily that interests are built up from embryo interests that exist already. He allows too little to the power of curriculum subjects or curriculum activities, given good teaching, to create interests that did not exist already.

All this reinforces Raz's claim that how much adequacy is required is a difficult problem that depends on particular circumstances.

\section{So how has what you have learnt from Raz and Callan affected your views on education, especially your views on the range of options available to the learner?}

The answer is complex. I'd like to build up the argument in three stages, the later ones dealing with objections raised by the one before.

[1] Children from an early age usually show an interest in pursuing certain things, often differing from individual to individual, like making things, games and physical activities, exploring the environment, interacting with friends and family members, playing with imaginary companions, watching comics on TV... Callan is right that we could do more in schools as elsewhere in education to encourage children to develop these interests (Callan 1988: 61-2), although whether this is true of every interest that a child pursues is, as Callan implies, doubtful, given that it may be immoral, imprudent or too trivial to count as worthwhile (p.66). 
What is it to develop an interest and not merely pursue it? For Callan it implies having the 'desire to understand my world more deeply' (p.61), or - what seems different - coming to have 'a deepening understanding of its [the interest's] object, as well as a desire for such understanding' (p.62). The stress on understanding may be tilting things too much in an intellectual direction. A girl of six may be crazy about doing handstands and back bend flipovers. Perhaps she gets further into this. She performs her moves more and more smoothly, adds to them, badgers her parents to arrange gymnastic classes for her. Deepening understanding is certainly a part of her development, but it is not the whole of it. Acquiring new physical abilities also comes into the picture. So, too, perhaps, does a change in her attitude or motivation: the desire for others' attention which was so evident in the early stages, while still present later, may be overlain by a more wholehearted concentration on the intrinsic demands of the activity.

The crucial thing for this paper is this wholeheartedness. This is because of the point I made earlier that 'a life of well-being is one in which the agent is wholeheartedly and successfully engaged in intrinsically worthwhile activities and relationships'. If a school or other educational agency helps a child to develop her interests in something in this direction, it enlarges the range of worthwhile options from which she can choose - perhaps into her adult years unless she has already given up this interest. This is no small benefit, educationally speaking. Too many children pass through school without experiencing this kind of engagement. This is true not least of many of the most diligent scholars - whose minds may be more on success in meeting their parents' and teachers' expectations, on high places in class, or good test results, than on the intrinsic goods of what they are studying. Creating the conditions for wholehearted immersion in interesting activities should be a vital task for any school, as well as any family or other agency with its children's well-being at heart.

That's the first stage of the argument.

\section{And the second?}

[2] Some people, like Callan's child with the artistic inclinations, may be lucky enough to be able to pursue into their later life the interests which their education has helped them to develop. Others may not be so lucky: there may not be enough paid work for talented writers or gymnasts or experts on the history of the camera; and they may find themselves short of the free time and resources they need to pursue these things. Another role of agencies educating for autonomous well-being is to expand their horizons beyond their current interests to embrace others which they may wish to pursue in the direction mentioned.

Some of these will be intellectual, that is concerned with the pursuit of truth in different areas; others will be artistic; and others practical in more than one sense. The first has to do with bodily skills, including whole body skills like acting or sports as well as manipulative skills involved in activities like making things. The other goes wider to encompass other means-end projects like coding or work on behalf of the school or other communities. There are, of course, all sorts of overlaps between all the activities described in this paragraph. 
I hope it is clear enough by now that there are no good reasons why schools or other agencies should be duty bound to extend these options as far as possible. They will do well if children end up with a handful of new interests in which they become enthusiastically involved, sometimes having to give up one activity to make room for something else which they like better. Added to their original interests under [1], this enlarges the range of worthwhile preferences children can carry into their adult years and with luck will have the time, resources and vocational opportunities to pursue some of them.

All this suggests a further role for educational agencies beyond the nurturing of interests children already possess described in [1]. Schools, for instance, could ask students to choose options from a range on offer, perhaps - or perhaps not - with some kind of restriction: perhaps, for example, their choices must include something intellectual, artistic and practical. The purpose would be to introduce children to an activity over a period - perhaps a year, perhaps less - to see if they want to take it further. Where they do, the school provides a more advanced induction. Where they don't, they should be allowed to take it further in a later year. In [2], as in [1], nurturing an intrinsic interest in pursuits is the central consideration. $^{2}$

You've just used the word 'pursuits' rather than 'activities'. Should we attach any importance to that?

Yes. I wrote 'pursuits' in the last sentence because I wanted a term that goes wider than 'activities'. As we have seen, personal well-being also covers successful engagement in worthwhile relationships; and for nearly all of us, this is a central element in our flourishing. Families naturally play a big part in laying the foundations for it, but schools also have a role. The relationships that make for a fulfilling life can be intimate as with friends and lovers, or more arms-length as with colleagues and neighbours. Schools have often ignored or even looked askance at close friendships among students, as if their sole business were with academic matters. Given the salience of intimate relationships in well-being and the pivotal place of well-being aims of education noted above, this makes little sense. Since most young schoolchildren have close friends, Callan's suggestion in [1] about schools encouraging students to develop their existing interests covers these personal interests too. Where children are poor at making friends, [2] comes into play: they can be engaged, for instance, in various social activities in which friendship is encouraged. As for the less intimate relationships we have later in life with colleagues and neighbours, schools can do a lot to foreshadow and prepare students for these via various cooperative activities and via the wider ethos of the institution. I realise there is much more to say elsewhere about the issues raised in this paragraph. ${ }^{3}$

Coming back to schools, as I understand your position in [1] and [2] compulsory lessons haven't come into the picture. The nearest you've got to this is to say that children have to choose something from a range of options. But so far all this is very different from what we usually find in schools - that certain subjects (perhaps indeed most or all subjects) are obligatory. Have I understood you correctly? 
Spot on. This brings me to my third stage [3]. [1] and [2], with their focus on developing or adding to existing intrinsic interests without resort - as you say - to compulsory lessons in a particular subject matter, may not be enough together to lay the educational foundations for providing adequate options for autonomous well-being. We come back to the point made at the beginning of [2], that some children, however wholeheartedly involved they become in what they are doing, may not be lucky enough to be able to carry this involvement into their adult life. They may, for instance, have to make do with boring jobs that leave them too little time, energy and/or money to pursue their enthusiasms in their free time. [3] suggests extending their range of possible options further in a vocational direction. Many of us gain great personal fulfilment from the job we do. Some students may make a career around an activity or activities in [1] and [2], but others may not. In an advanced economy like our own many of the most potentially absorbing jobs depend to different degrees on such things as good literacy, computing skills and competence in a STEM subject, as well as on the ability to work well in a team. These jobs cover a huge range from working as a gardener, builder or research scientist to being a journalist or electrician. Whereas neither [1] nor [2] require compulsory classes, there may be a case based on adequacy of options for literacy and other activities like those mentioned to be compulsory.

\section{So we come back to compulsory subjects after all?}

Not necessarily. Compulsory activities need not be subjects in the academic sense. I've said, for instance, that they might include ability to work well in a team. There is a good reason, given our context of education for autonomous well-being, why any compulsory pursuit should be taught in as appealing a way as possible. The aim here is seduction - to get learners caught up in the intrinsic delights of an activity in which much of their life may be spent. Sometimes discrete subject teaching may fit this bill; but just as often or even more often, perhaps, interdisciplinary project-based work may be more suitable. ${ }^{4}$ This is especially worth considering, given the vocational aims we now have in mind. Projects lend themselves to cooperative team work; and they are a good way of bringing in the wider economic, social and political horizons that provide much of the framework in which their later paid employment may well take place.

How long should literacy, computing skills, science etc be compulsory for? As things stand now in schools in England - and the same is true in many other countries - so-called 'basic subjects' like these have to be studied for all or most of one's whole school career. This, as we know, can often lead to a low level of interest or even boredom. ${ }^{5}$ This is massively counter-productive if seduction is our aim. We should rethink the assumption just mentioned that the 'basics' must be taught for ten years or more. In addition, it might often be better to allow students for whom mathematics (say) has become unappealing, to be able to drop it once the content has gone beyond basic arithmetic and is moving into more advanced areas. (See Reiss and White 2013: 18). They could be allowed, for instance, to use the time now freed up to pursue other intrinsic interests of theirs.

In [3], I have stressed literacy and STEM subjects as examples of possible compulsory activities, but do not mean to be dogmatic. The question of what activities should be compulsory is complex and goes beyond vocational concerns - indeed, it links with Raz's point that the adequacy issue is enormously difficult. It needs a fuller discussion beyond the bounds of a short paper. 


\section{Are [1], [2] and [3] therefore sufficient in providing young people with an adequate range of worthwhile options as a basis for a life of autonomous well-being?}

As I see it, something like this would indeed be what is wanted. The range falls between those of the 'all possible options' view and Callan's interest-based view, being much closer to the latter. ${ }^{6}$

There is more to say elsewhere, I should add, about other requirements of education for autonomous well-being not directly concerned with extending options. It should include, for instance, some compulsory background understanding of the social, including political, and natural worlds within which all of us lead our lives (Reiss and White 2013: 9, 11-12). [This may well overlap with items in [1] - [3] - like the study of science needed for vocational reasons]. It should also create time for students, especially older ones, to think about priorities among their chosen goals and conflicts among them, as well as how instrumental and constituent sub-goals as well as considerations about need-satisfactions fit into their value hierarchies, at the apex of which are the most important of their chosen goals.

\section{How much of a challenge to the status quo is your new notion of education for well- being?}

I think what is striking about it is how it reverses the priorities so often found in standard school curricula. It attends more fully to the needs of individual children, putting their wholehearted involvement in self-chosen intrinsically valuable activities at the centre and reducing compulsory, especially subject-based, learning to much less than now.

Education for autonomous well-being is time-consuming. Taking the first steps as children on the road to choosing worthwhile options that may - or may not - be enjoyed throughout their lives is a slow process. How do they become engaged in these options? Like the little girl who loves handstands, children are drawn into them gradually as they come to make them their own. This kind of choice takes time. It is a world away from speedy decisions made in a supermarket; different, too, from those often made in politics and business.

It is time-consuming in several ways - in tentatively entering into an activity, in pursuing it with enthusiasm once one has some mastery of it, in thinking through one's priorities as an older child when drawn into more and more things that absorb one. Schools, like families, should allow children plenty of time to themselves for these explorations. This is essential if they are to learn what it is to lead a flourishing life. It is sad that schools as we know them too often see it as their duty to fill children's days with compulsory, teacher-initiated activities. It may be that they are still under the sway of religious ideas that were until relatively recently so influential in our schools. These called for children to be kept busy and under surveillance in case, if alone, they got up to mischief, fell into sin. John Wesley, for instance, who packed the timetable of his Kingswood School near Bristol with academic subjects across a wide range, famously wrote that we do not 'allow any time for play on any day' (Wesley 1749: 5). It is time that the puritan work ethic which still dominates our school system, not least in its thraldom to tests and exams, gave way to an ethic of autonomous well-being. 


\section{Is school reform enough on its own, in your view? Or would you also press for wider social changes?}

No, I don't think it is all we need. Suppose schools and other educational agencies are successful and every child leaves school wholeheartedly involved in a small number of worthwhile activities and close relationships which set them on the road to a flourishing life. Whether they will in fact lead such a life largely depends on how far the institutions of their society facilitate this. As was said above (p.•), adequacy of options has to do with the options available to people in the circumstances in which they find themselves.

They may be in the lucky minority who go to university or into apprenticeships and then into jobs that are personally fulfilling. If they are not so lucky, they may find themselves in work of some mind-crushing or exhausting kind that leaves them little time and energy after work to engage in valuable activities - which, as we have seen, depends on having plenty of time to oneself.

These people, remember, have had an ideal education. This has left them with experience of what a life of autonomous well-being consists in, even if they now lack the opportunity to engage in it beyond close relationships within the family and with friends. As things are in the real world, however, those outside the lucky minority have often had, from a well-being perspective, an impoverished education. This leaves them potential victims of those who want to persuade them, misleadingly, that the good life is within their reach. Advertisers and other manipulators together instil the message that happiness, living life to the full is found in serial addiction to clothes, gadgets, food, drink, beauty treatments, meals out, other consumer goods, fun in the sun, being the object of attention on social media, watching favourite TV programmes, identifying with successful sportspeople, singers and other celebrities. These delights are often short-lasting and easy to engage in after eight hours of unfulfilling work. In this they are almost polar opposites of worthwhile pursuits. Unlike these, gardening, reading novels, going swimming or working in local politics are 'lifebuilding' activities, to re-invoke this expression, as well as usually time-consuming and dependent on acquired skills and understandings. Granted, those I have called the lucky ones, who do live a genuinely fulfilling life, all enjoy some of the short-lasting pleasures mentioned. But they see them not as constituting the core of their well-being, but only as a pleasant or fun-filled periphery. For the unlucky ones, relationships apart, there is often little else in their world from which to choose. Realisable worthwhile options are, for them, too often inadequate.

So, no, education is not enough. There must indeed be broader social changes. Those of us in philosophy of education cannot remain cosily within the walls of our own discipline, without attending to the political ramifications of our ideas. We may lack the expertise to explore these in detail, but I hope this paper has shown that the little work that has yet been done on what may seem to some a dry or insignificant topic - the adequacy of options - has implications not only for school reform but also for social reform more widely. For this reason, further philosophical exploration of this area would be welcome. 


\section{Notes}

${ }^{1}$ Raz returns to the role of capacities in providing adequacy of options issue in 'Duties of Well-Being' (Raz 1994: 16-17). But whereas in Raz 1986, as shown from the quotation in my text from p.375, he invokes capacities to define what counts as adequacy, in Raz 1994 his focus is educational. His 'Basic-Capacities Principle' 'requires us to promote conditions in which people have the basic capacities for the pursuit of goals and relationships of sufficient range to make for a rewarding and fulfilling life.' He says a little, but nothing very substantial, about what these basic capacities should be. But see Note 6 below.

${ }^{2}$ A partial historical model for these optional activities is found in the Pioneer Houses and Palaces of the former Soviet Union. I visited one of these in Leningrad in 1959-60 and was hugely impressed. (See White 1973: 70, and note 2; Reiss and White 2013: 55). A contemporary model is the Free-semester Program recently introduced in all South Korean middle schools. (See

http://m.koreatimes.co.kr/phone/news/view.jsp?req newsidx=153135 ). I am grateful to Sangeun Lee from the Center for Free-semester Program in Seoul for drawing this to my attention.

${ }^{3}$ Education is not only about equipping learners for a life of well-being. Another major aim, embracing many sub-aims, is equipping learners to help other people to lead such a life. I do not discuss that aim in this interview. But mention of friendship and cooperative activities reminds us that self-orientated and otherorientated concerns are not mutually exclusive. So does what I go on to say about vocational education.

4 See 'Finland schools: Subjects scrapped and replaced with 'topics' as country reforms its education system' Independent 20 March 2015 http://www.independent.co.uk/news/world/europe/finland-schools-subjectsare-out-and-topics-are-in-as-country-reforms-its-education-system-10123911.htm

${ }^{5}$ Some evidence for this is in the 2015 Report from TIMMS (International Trends in Maths and Science Study). This shows a significant drop in English students' enjoyment of maths between the ages of 9/10 (Year 5 ) and 13/14 (Year 9). See Toby Greany's IOE London Blog of June 202017

https://ioelondonblog.wordpress.com/2017/06/20/does-enjoyment-go-down-as-achievement-goes-up-findings-from-timss-on-howpupil-attitudes-to-maths-and-science-have-changed-over-20-years/\#more-7552

${ }^{6}$ The paragraph from Raz (1994: 16-17) mentioned in Note 1 makes an important point - in footnote 16 - that is more in line with Callan's approach than with the 'all possible options' one. It says that the Basic-Capacities Principle 'does not require that everyone should have the same capacities, so long as each person has adequate capacities'. In the main text (p.17), Raz writes 'Not all capacities are required. I have never suffered from not having the capacity to acquire the skills of an airline pilot. But I had enough other capacities.'

\section{References}

Callan, E. (1988) Autonomy and Schooling Montreal: McGill-Queen's Press

Rawls, J. (1972) A Theory of Justice Oxford: Oxford University Press

Raz, J. (1986) The Morality of Freedom Oxford: Oxford University Press 
(1994) Ethics in the Public Domain Oxford: Clarendon Press

------ (2003) The Practice of Value (The Berkeley Tanner Lectures)

Reiss, M. and White, J. (2013) An Aims-based Curriculum London: IOE Press

Thompson, K. and White, J. (1975 ) Curriculum Development: A Dialogue London: Pitman

Wesley, J. (1749) A Short Account of the School in Kingswood, in Ives, A.G. (1970)

Kingswood School in Wesley's day and since (pp.11-18) London: Epworth

White, J. (1973) Towards a Compulsory Curriculum London: Routledge and Kegan Paul

(1982) The Aims of Education Restated London: Routledge and Kegan Paul 